\title{
ESTUDANDO FRAÇÕES: DESENVOLVIMENTO DE UM SOFTWARE EDUCATIVO PARA APRENDIZAGEM DE FRAÇÕES MATEMÁTICAS
}

\author{
Franciely Alves de Souza, Hígor R. Monteiro Santos e Adauto T. Almeida Filho, \\ Célia Cristina Vilela da Silva
}

\author{
Universidade de Pernambuco, Campus Garanhuns (UPE), CEP 55.294-902, PE - Brazil \\ \{francielyalves835, celinhacristina20\}@gmail.com, \{higor.monteiro@, \\ adauto.filho\} @upe.br
}

\begin{abstract}
This article reports the experience of the undergraduate students in Computing at the University of Pernambuco during Supervised Internship III, focusing on the development of educational software. Thus, the undergraduates acted as developers and applicators of educational software focused on teaching mathematical fractions.
\end{abstract}

Resumo. Este artigo relata a experiência vivenciada pelos licenciandos em Computação da Universidade de Pernambuco durante a disciplina de Estágio Supervisionado III, com foco em desenvolvimento de softwares educativos. Dessa forma, os licenciandos atuaram como desenvolvedores e aplicadores de um software educativo com foco no ensino de frações matemáticas.

\section{Introdução}

Segundo Scaico (2012), a tecnologia digital está amplamente inserida na sociedade moderna, alterando hábitos profissionais, de entretenimento e estudos das pessoas.Diante disso, aproveitamos o grande interesse do público por tais tecnologias, e propomos um software para o ensino de conceitos matemáticos. O presente trabalho apresenta o relato de desenvolvimento e aplicação de um Software Educativo (SE), sobre o conteúdo de frações, voltado aos alunos do $6^{\circ}$ ano do Ensino Fundamental.

A escolha de desenvolver uma proposta voltada ao conteúdo de Frações ocorreu por reconhecer que se trata de um assunto que os alunos da Educação Básica apresentam muitas dificuldades, tanto relacionadas ao entendimento do significado dos números racionais (na forma de fração), quanto aos tipos de frações existentes e às operações de adição, soma, multiplicação e divisão com esses números. Desta forma, percebeu-se necessário encontrar uma forma diferente de abordar esse conteúdo, com o intuito de fomentar a melhoria da aprendizagem de frações.

Nesse contexto, o presente artigo relata a experiência de discentes do Curso de Licenciatura em Computação, da Universidade de Pernambuco, Campus Garanhuns, que através do projeto de Estágio Supervisionado III, que é focado no desenvolvimento de SE, atuaram como desenvolvedores e aplicadores de um SE no âmbito escolar.

O artigo está estruturado em 6 seções. Além da introdução que apresenta o contexto, a Seção 2 apresenta trabalhos relacionados com destaque para softwares para o ensino matemático. A Seção 3 detalha a importância do estágio supervisionado, para a 
VIII Congresso Brasileiro de Informática na Educação (CBIE 2019)

Anais do XXV Workshop de Informática na Escola (WIE 2019)

licenciatura em Computação. A Seção 4 detalha o relato de experiência. A Seção 5 detalha os resultados obtidos após a aplicação do software. Por fim, a Seção 6 descreve as considerações finais e seguido das referências.

\section{Trabalhos Relacionados}

$\mathrm{Na}$ literatura é possível encontrar alguns trabalhos relacionados a este aqui apresentado. A pesquisa de SARMENTO et al. (2017) mostra como um jogo matemático pode contribuir para o desenvolvimento cognitivo e social do aluno, apontando a importância do jogo como ferramenta constituinte no processo de aprendizagem do aluno.

BARBOSA et al. (2009) detalham a experiência da utilização dos jogos matemáticos como uma estratégia desencadeadora do processo de ensino e aprendizagem. $\mathrm{Na}$ sala de aula é utilizado como um recurso pedagógico que cria situações que permitem ao aluno desenvolver métodos de solução de problemas. Estimulando, desta forma, a sua criatividade e participação.

Já SOUZA et al. (2018) abordam como ponto principal a problemática existente com o aprendizado de Matemática. Os autores relatam o processo de desenvolvimento de um jogo educativo com foco em Matemática, intitulado "Operação Monstro" que através de seu ambiente lúdico, visa proporcionar um aprendizado atrativo.

Como também é destacado por BELTRAME et al. (2017) que mostram que parte dos alunos que ingressam no ensino médio apresentam dificuldades com operações básicas de matemática. E propõe como forma de solução um aplicativo móvel na forma de um jogo lúdico, denominado Aventura Matemática, que permite ao aluno explorar cenários enquanto navega por desafios de operações básicas.

Diante dos trabalhos citados, o presente artigo busca incorporar uma nova ferramenta que possibilite o desenvolvimento da aprendizagem, focada nos conteúdos de frações, onde são proporcionadas atividades lúdicas e engajadoras. Os principais diferenciais deste trabalho, são a sua facilidade de uso, por possui um ambiente interativo, podendo ser utilizado dentro do âmbito da sala de aula com o acompanhamento do professor, como também pode ser utilizado para aprendizagem e exercício fora do ambiente educacional, onde os usuários podem estudar os conteúdos.

\section{Estágio Supervisionado em Licenciatura em Computação}

A disciplina de Estágio é obrigatória e encontra-se presente na maioria dos cursos superiores, pois propicia o contato dos discentes estagiários com o meio profissional. Em vista disso, temos a construção do conhecimento que colabora efetivamente com a formação profissional, como é destacado por Scaico (2012).

A Licenciatura em Computação propõe-se a formar professores para atuarem no ensino de computação em todas as suas modalidades e níveis de ensino. O curso objetiva atender à necessidade imediata de informatização e de avanços dessa área nos diversos setores da sociedade. Além disso, o licenciado em Computação também é capacitado para desenvolver softwares educativos, aplicação e gestão de tecnologias de informação e comunicação no ambiente educacional. Nesse sentido, o componente curricular de Estágio Supervisionado do Curso de Licenciatura em Computação, do sétimo período, objetivou proporcionar aos discentes, situações da vivência profissional no desenvolvimento de softwares voltados a educação. 
VIII Congresso Brasileiro de Informática na Educação (CBIE 2019)

Anais do XXV Workshop de Informática na Escola (WIE 2019)

Dessa forma, foi desenvolvido o Objeto de Aprendizagem (O.A) denominado Estudando Frações. Ele foi desenvolvido na linguagem de programação JAVA, baseado em softwares educacionais de exercício e prática, que visam ensinar os conceitos de frações, com atividades práticas. A Figura 1 mostra as opções de interação disponíveis para o usuário.

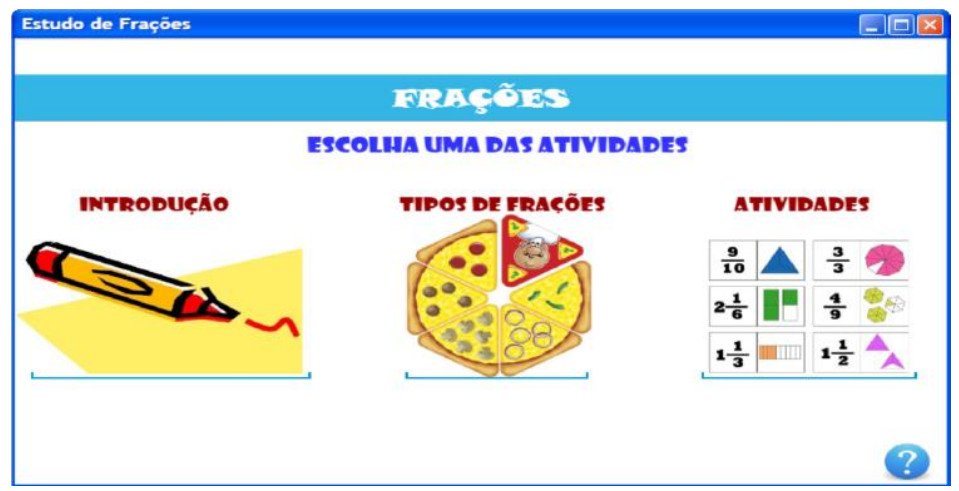

Figura 1. Tela principal do O.A

O software possibilita o aprendizado de Frações através de uma introdução geral sobre o contexto, para em seguida tratar individualmente cada tipo de fração. Os tipos de frações contidas no O.A são: fração própria, imprópria, mista e aparente, onde para cada uma contém uma respectiva atividade prática relacionada.

\section{Relato da Experiência}

Esta seção descreve o relato de experiência desde a etapa do planejamento do software até seu desenvolvimento e testes de usabilidade com usuários. A experiência de planejar e desenvolver um software educativo foi um grande desafio, uma vez que se trata de um O.A que possui um público jovem. Dessa forma, foi necessário trabalhar estratégias para manter a atenção do usuário na aplicação, com intuito de suprir suas dificuldades diante do contexto trabalhado.

Os devidos problemas foram identificados através de experiências dos licenciandos como docentes em sala de aula, tais experiências foram adquiridas em estágios anteriores, no qual eram voltados para o ensino de Computação Interdisciplinar, onde foi possível observar a dificuldades dos alunos para compreender devidos conceitos matemáticos apenas com o uso de livro didático. A principal função do software desenvolvido é favorecer para o público-alvo um aprendizado prático que trabalha com contextos e representações do dia a dia.

Trabalhar com softwares na sala de aula proporciona para o aluno um momento lúdico despertando curiosidade para se aprender. Desta forma, tal recurso, proporciona um aprendizado atrativo. O software não possui complexidade para o uso, porém é necessário que, antes de ser utilizado, os alunos possuam um conhecimento inicial sobre o contexto de frações. Para então, utilizá-lo como ferramenta de auxílio para estudar, praticar exercícios e revisar os conteúdos.

Para trabalhar os conteúdos implementados no software, foi planejado que para cada tipo de fração, seria apresentada uma descrição e ilustrações representativas, para facilitar o entendimento do contexto. A Figura 2 ilustra como os tipos de frações são apresentados para os usuários. 
VIII Congresso Brasileiro de Informática na Educação (CBIE 2019)

Anais do XXV Workshop de Informática na Escola (WIE 2019)

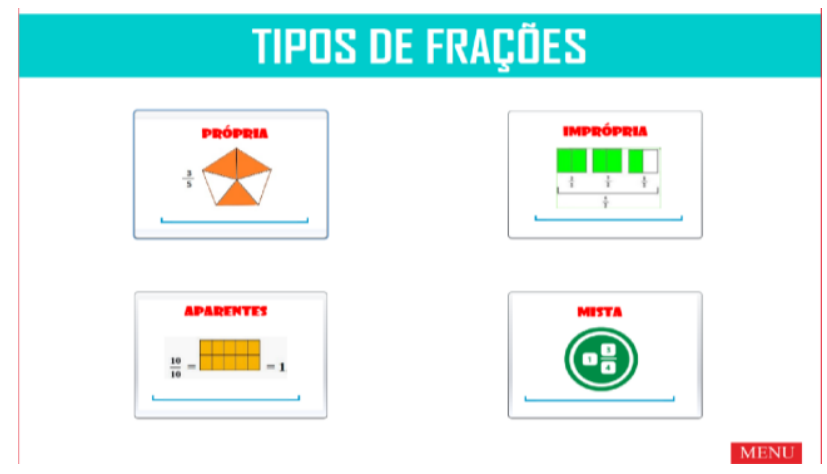

Figura 2. Tela dos conteúdos de Frações.

O intuito de apresentar cada tipo de fração separadamente é uma estratégia para passar autonomia para os usuários. Sendo assim, poderão escolher como pretendem iniciar seus estudos. Ao planejar e desenvolver um software educativo, o intuito é criar novos procedimentos de ensino que possam auxiliar no processo de ensino-aprendizagem com a utilização da tecnologia.

\section{Resultados}

Diante do contexto do Estágio Supervisionado, precisava-se de usuários para fazer uso do software desenvolvido, visando obter resultados de um teste de usabilidade sobre suas funcionalidades, e também avaliar se o contexto de frações está bem representado para o processo de aprendizado. Buscou-se analisar possíveis melhorias citadas pelos usuários, para então serem implementadas, com isso optou-se por buscar alunos que já tivessem algum contato com o computador para que conseguissem utilizar e compreender o funcionamento do software. Os 18 alunos participantes, são estudantes da Escola de Escola de Aplicação Professora Ivonita Alves Guerra, cursam o $7^{\circ}$ ano, e possuem de 11 a 12 anos de idade.

As atividades apresentadas no SE foram desenvolvidas para serem facilitadoras na interação aluno/professor/conhecimento. Para validar as funcionalidades do software, os alunos responderam um questionário com quatro assertivas, que buscam analisar o quanto é fácil interagir com as funcionalidades do mesmo, e o quanto contribuiu no aprendizado. Cada aluno utilizou o software, por aproximadamente vinte minutos, sendo assim, obteve-se os resultados mostrados no Gráfico 1.

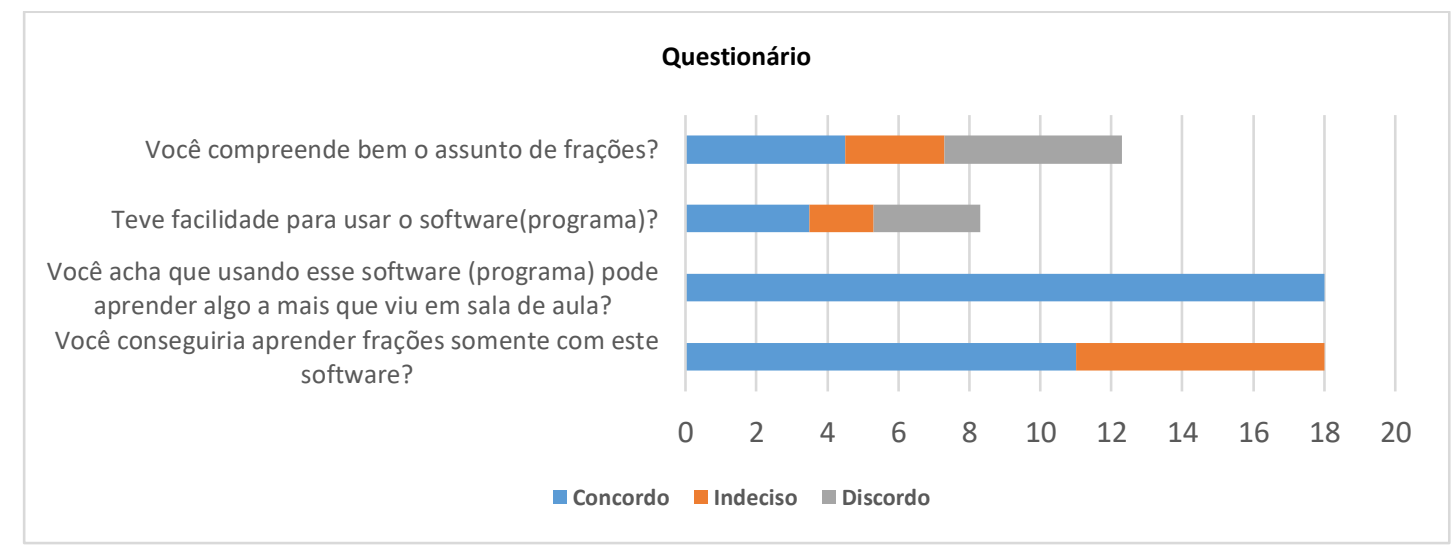

Gráfico 1. Dados adquiridos através do Questionário 
VIII Congresso Brasileiro de Informática na Educação (CBIE 2019)

Anais do XXV Workshop de Informática na Escola (WIE 2019)

Ao observar a interação dos alunos todos se mostraram bastante engajados em praticar os exercícios com o uso do computador. Evidenciou-se que as atividades se tornaram mais prazerosas com o envolvimento da tecnologia. Diante dos resultados obtidos, a avaliação do software foi satisfatória, o qual possui interfaces de fácil compreensão e funcionalidades simples, que busca representar o conteúdo de forma compreensível e atrativa, contendo um conjunto de atividades práticas para testar os conhecimentos adquiridos nos estudos efetuados.

\section{Considerações finais}

Diante do estudo realizado e dados obtidos na pesquisa, pode-se afirmar a importância que os SE podem agregar ao processo de ensino e aprendizagem. Nesta pesquisa, essa tecnologia, se deu de forma bastante satisfatória colaborando para o aprendizado dos alunos participantes. Sendo assim, é possível reconhecer que o SE se torna um fator motivador para o aprendizado como mediador pedagógico no estudo da Matemática com sua linguagem dinâmica e apresenta fatores que gera grande aceitação entre os alunos.

Sugere-se, para as possibilidades de trabalhos futuros, uma intervenção com um número maior de participantes. Além disso, realizar um trabalho comparativo, com duas realidades diferentes, uma com acesso tecnológico aliado aos conteúdos escolares e outra somente com o ensino tradicional. Assim como, a criação de uma nova versão do SE, no qual poderíamos trabalhar com o acréscimo de novos recursos, como: animações 3D e vídeos aulas. Em vista disso, pode-se considerar, que os SE são de grande importância para os estudantes, professores e pesquisadores, que buscam por recursos computacionais para melhorarem suas aulas e práticas pedagógicas.

\section{Referências}

BARBOSA et al. (2009), "Jogos Matemáticos como Metodologia de Ensino Aprendizagem das Operações com Números Inteiros", Londrina.

BELTRAME, W et al. (2017), “Aventura Matemática: Demonstração e Avaliação de um Aplicativo para Aprendizagem de Operações Básicas”. In: Anais dos Workshops do Congresso Brasileiro de Informática na Educação.

SARMENTO et al. (2017) "A importância dos jogos matemáticos para a aprendizagem: aplicação do jogo conhecendo a equação no ensino médio". Disponível em < https://semanaacademica.org.br/system/files/artigos/a_importancia_dos_jogos_ma te maticos_para_a_aprendizagem_0.pdf>. Acessado em 30/09/2018.

SCAICO, P. D.et al. (2012) Relato da Utilização de uma Metodologia de Trabalho para o Ensino de Ciência da Computação no Ensino Médio. In: Anais do Workshop de Informática na Escola, Curitiba - PR.

SCAICO, P. D., Henrique, M. S., Cunha, F. O. M., \& de Alencar, Y. M. (2012) "Um Relato de Experiências de Estagiários da Licenciatura em Computação com o Ensino de Computação para Crianças".

SOUZA, F. A. de; SANTOS, B. B. dos; SILVA, M. R. B. da; RODRIGUES, A. N; BARRETO, F. F. Processo de Desenvolvimento de um jogo sério para o ensino das Quatro Operações Matemáticas. Anais dos Workshops do VII Congresso Brasileiro de Informática na Educação (WCBIE 2018). 